\title{
O Federal Reserve (FED) no palco central: navegando por águas proibidas
}

\author{
The Federal Reserve (FED) on main stage: navigating by forbidden waters
}

\section{Gérard Duménil ${ }^{a}$ Dominique Lévy ${ }^{b}$}

\begin{abstract}
Resumo: A principal ameaça iminente da pandemia à economia dos EUA é o aumento do endividamento das empresas e do governo. O Federal Reserve agiu de forma espetacular no apoio ao crédito, e este é apenas o começo de uma longa história. O apoio dos mecanismos de crédito pelo Federal Reserve já estava em andamento antes da crise da COVID-19. Novos graus foram alcançados e novos caminhos estão sendo abertos atualmente, como empréstimos diretos às empresas pelo FED. Os limites são, no entanto, cumpridos por razões políticas e ideológicas: Conforme mencionado anteriormente, não havia uma política voltada à preservação da receita de vendas das empresas. A continuação da nova trajetória de taxas de juros muito baixas e o financiamento direto do Federal Reserve enfrentará fortes resistências por parte de interesses financeiros. Isso transformaria os bancos como credores em meros intermediários na concessão de empréstimos (cobrança de taxas aos mutuários), como já é o caso da intermediação financeira não-bancária.
\end{abstract}

Palavras-chave: FED; Endividamento; Crédito; COVID-19

Classificação JEL: E42, E63, P16

\begin{abstract}
The main imminent threat of the pandemic to the US economy is the increase in corporate and government indebtedness. The Federal Reserve has acted spectacularly in supporting credit, and this is just the beginning of a long story. Federal Reserve support of credit mechanisms was already underway before the COVID-19 crisis. New grades have been reached and new paths are currently being opened, such as direct loans to companies by the FED. The limits are, however, enforced for political and ideological reasons: as mentioned earlier, there was no policy aimed at preserving the companies' sales revenue. The continuation of the new trajectory of very low interest rates and direct financing from the Federal Reserve will face strong resistance from financial interests. This would transform banks as lenders into mere intermediaries in granting loans (charging fees to borrowers), as is already the case with non-bank financial intermediation.
\end{abstract}

Keywords: FED; Indebtedness; Credit; COVID-19

JEL Classification: E42, E63, P16

\footnotetext{
${ }^{\text {a E}}$ Economista, ex-Diretor de Pesquisa do Centre National de la Recherche Scientifique (CNRS), na França. Colabora há muitos anos com o economista Dominique Lévy. Email: gerdumenil@ gmail.com.

${ }^{\mathrm{b}}$ Economista e membro do corpo editorial de Actuel Marx. Email: $\underline{\text { domi.levy@ free.fr. }}$
} 


\section{Introdução}

A principal ameaça iminente da pandemia à economia dos EUA é o aumento do endividamento das empresas e do governo. O Federal Reserve agiu de forma espetacular no apoio ao crédito, e este é apenas o começo de uma longa história. Superar a crise será um processo longo e incerto. A forte ação das autoridades centrais está em desacordo com a ideologia neoliberal, como também foi o caso no tratamento da crise de 2008. Dadas as atuais circunstâncias de baixas taxas de inflação, o ônus da dívida parece incompatível com o retorno a um "padrão normal” da macroeconomia, se existir tal padrão existir. Será a contração no nível de atividade seguida por uma onda de inflação?

Não há, contudo, uma avaliação possível das perspectivas independente das tendências insustentáveis de longo prazo da economia dos EUA já moldadas pela dinâmica de classe do neoliberalismo. O papel-chave do Federal Reserve no financiamento direto da macroeconomia começou após a crise de 2008-9. Esse processo não é causado pela crise da Covid, a qual funciona adicionando combustível ao fogo. Os dados necessários para uma avaliação completa da atual situação não estão disponíveis. A análise que segue é baseada nas informações possíveis de encontrar no presente momento.

\section{A Ameaça: Expansão do Endividamento do Governo e das Empresas}

O déficit orçamentário do Governo Federal dos EUA foi de 1.905 bilhões de dólares nos primeiros oito meses do ano fiscal de 2020, ou seja, 1.167 bilhões de dólares a mais do que o déficit registrado durante o mesmo período do ano passado. Isso foi causado pelo declínio da receita do Governo Federal e pelo aumento das despesas. A tabela 1 mostra o aumento de gastos de cerca de meio trilhão de dólares (com cerca de 50 por cento para o Fundo de Emergência dos Serviços Sociais de Saúde Pública) em Maio de 2020 em comparação com Maio de 2019. Como mostra a Figura 1, a tendência das despesas do governo aumentou fortemente na pandemia.

Tabela 1 - Gastos do governo dos EUA em apoio à economia, maio de 2020 (US\$ bi)

\begin{tabular}{lcc}
\hline \hline & Maio 2019 & Maio 2020 \\
\hline Seguro desemprego & 2 & 93 \\
Crédito tributário reembolsável & 3 & 53 \\
Administração de pequenas empresas & 0,0038 & 35 \\
Fundo de Emergência dos Serviços Sociais de Saúde Pública & 27 & 250 \\
Fundo de ajuda (doações para governos estaduais, locais, e territoriais) & 0 & 5 \\
Socorro aos trabalhadores da aviação & 0 & 5 \\
Fundos em investimento em participações pelo Federal Reserve & -47 & 54 \\
\hline \hline
\end{tabular}

Fonte: Bureau of the Fiscal Service, U.S. Department of the Treasury 


\section{Figura 1 - A dívida do governo estadunidense (US\$ trilhão)}

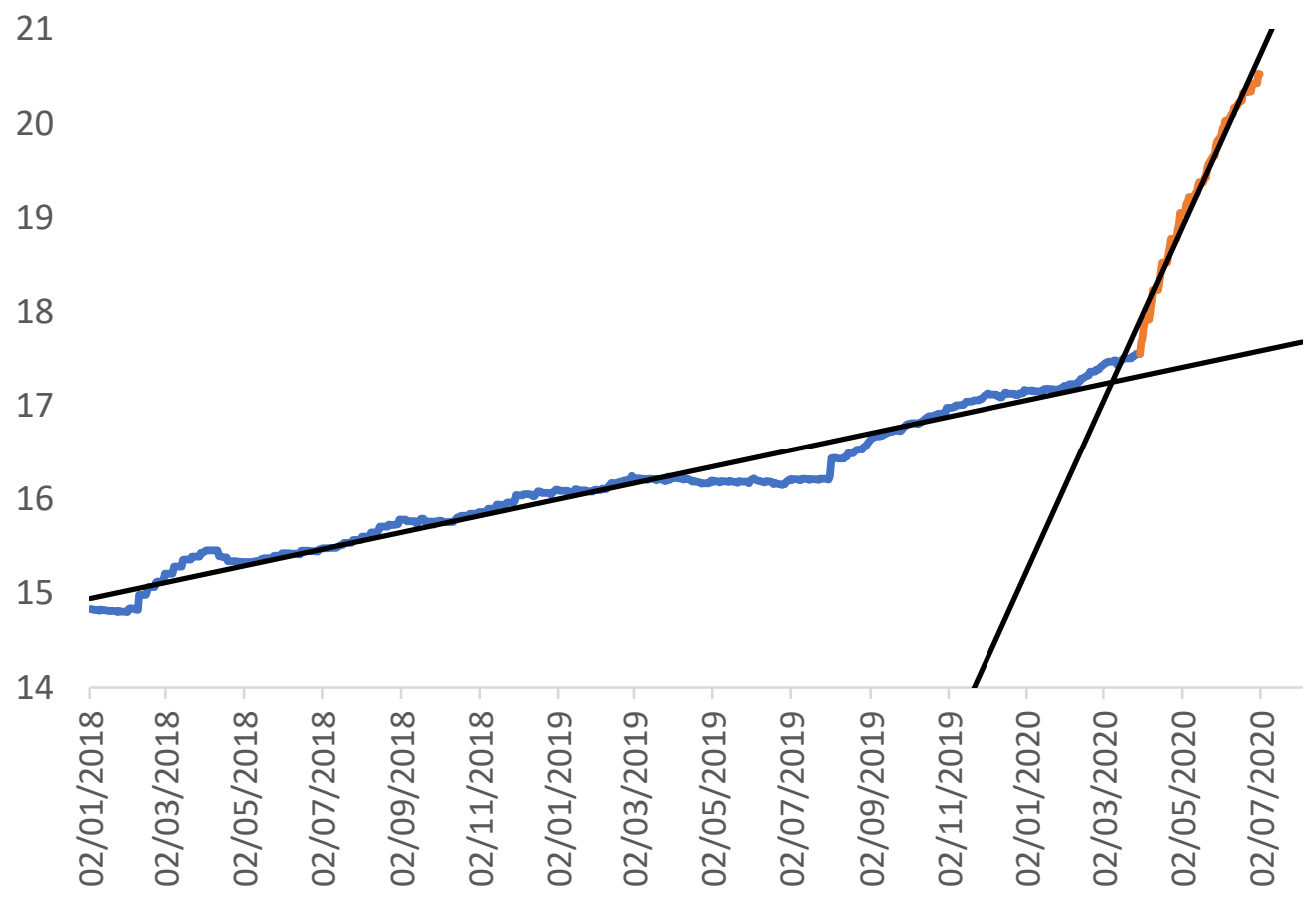

Fonte: Bureau of the Fiscal Service, U.S. Department of the Treasury (2020)

\subsection{A Dívida das Empresas: Empréstimos e Títulos de Dívida}

As empresas tomam empréstimos e emitem títulos de dívida (títulos). Desde a crise de 2008-9, a dívida das firmas em empréstimos (empréstimos comerciais e industriais), o estoque de empréstimos comerciais e industriais, possui uma tendência de alta, como geralmente ocorre durante os períodos em que a economia está entre as recessões. Um aumento repentino foi observado durante a pandemia, afetando em particular pequenos bancos e, consequentemente pequenas empresas. As grandes empresas emitiram títulos massivamente, como mostra a Figura 2. O fluxo no período foi multiplicado por um fator de quase três e meio. Por sua vez, os fluxos de emissões são considerados em vez dos estoques de empréstimos na Figura 3. 
Figura 2 - Emissões mensais de títulos de dívida por empresas, EUA, outubro/2017 - maio/2020 (US\$ bilhão)

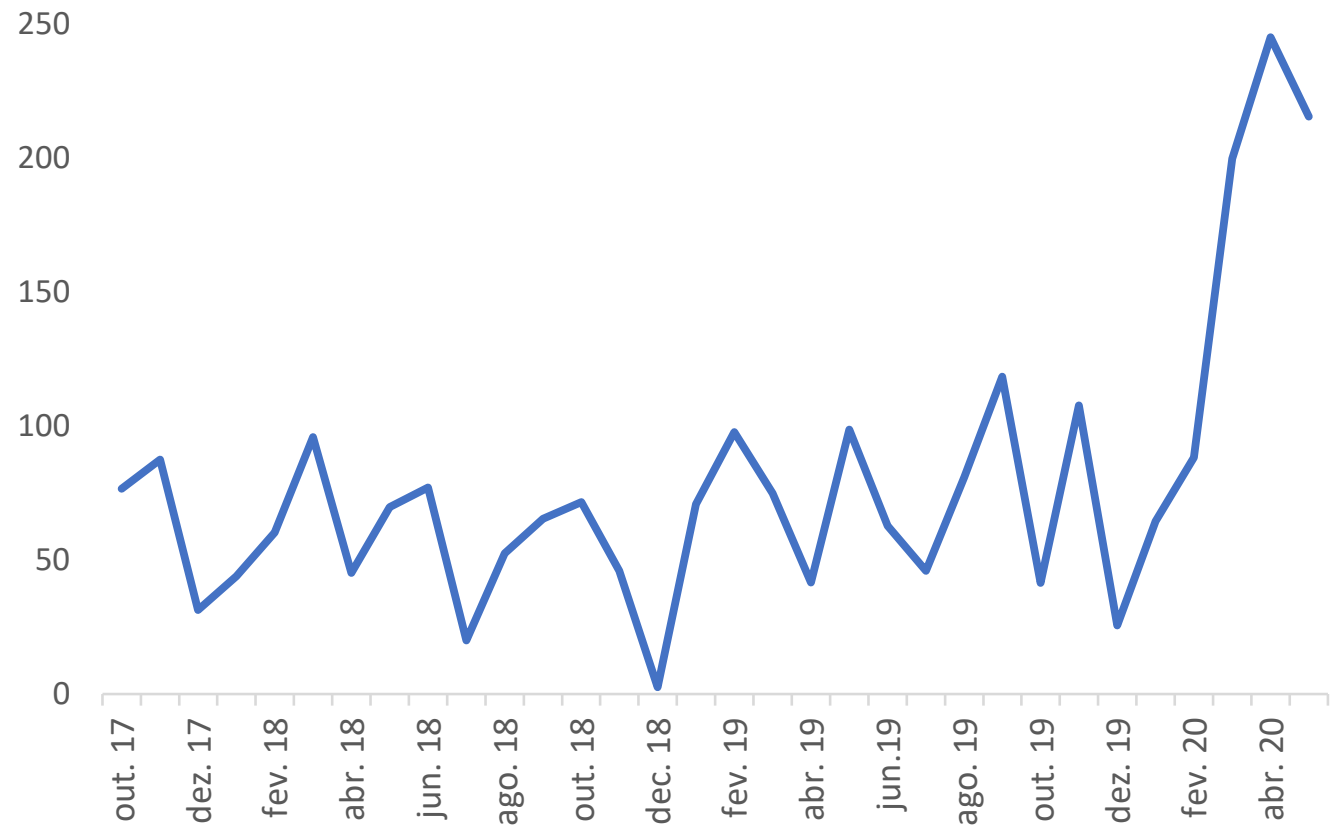

OBS: Emissões de títulos de corporações não-financeiras

Média entre outubro de 2017 e fevereiro de 2020: 64 US \$ bilhões

Média entre março de 2020 e maio de 2020: 218 US\$ bilhões

Fonte: Board of Governors of the Federal Reserve System (2020b). 
Figura 3: Empréstimos às empresas por instituições bancárias, EUA (US\$ bilhão)

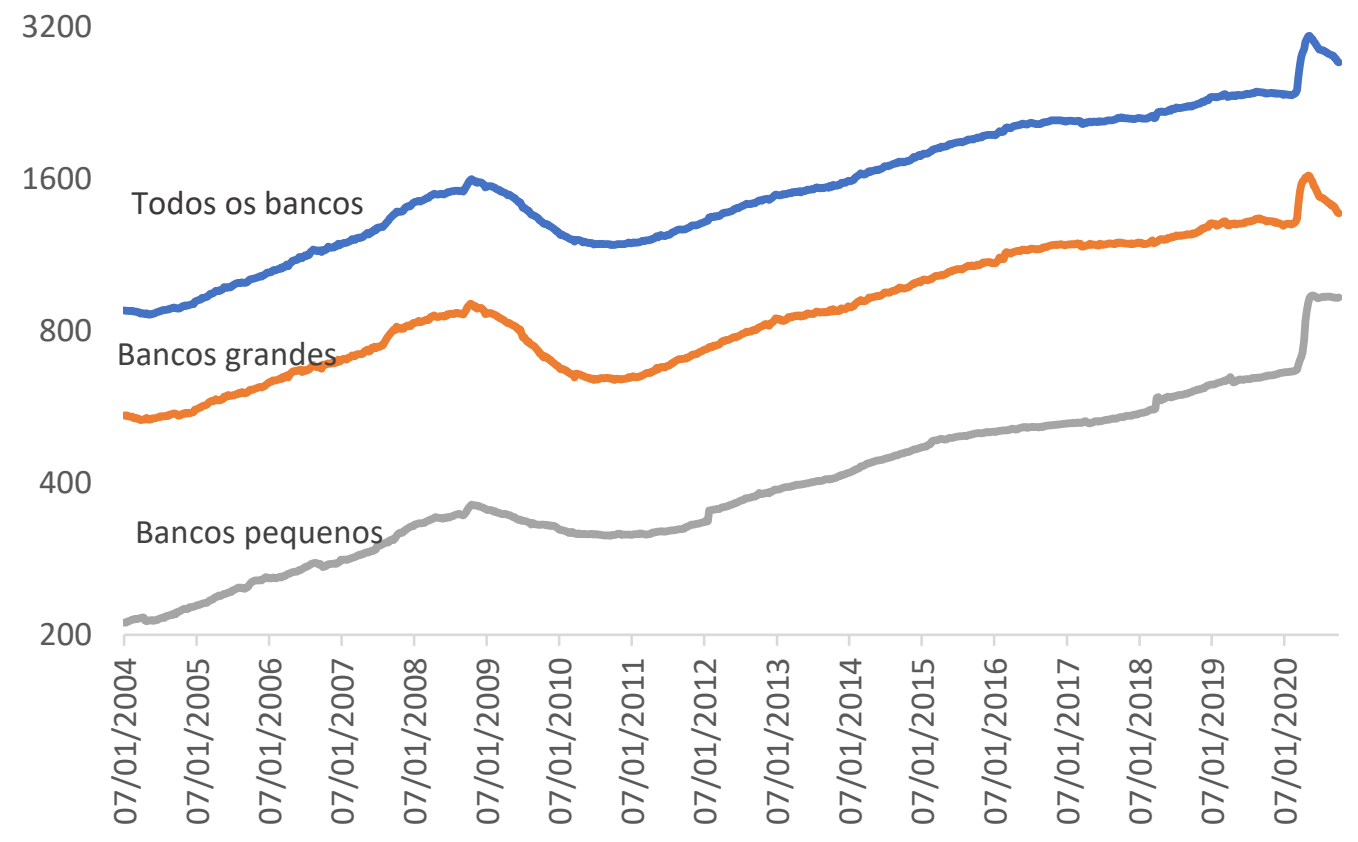

OBS: Ativos dos bancos comerciais: Empréstimos comerciais e industriais

Fonte: Federal Reserve St. Louis (2020)

\section{O Federal Reserve (FED) em Apoio às Dívidas Crescentes}

Como será discutido mais adiante, desde a crise de 2008-9, o Federal Reserve está envolvido massivamente no financiamento de títulos do governo. Vamos nos concentrar nos últimos momentos dessa ação que ocorreu durante a pandemia. Além do total, a primeira variável na Figura 4 é o total de títulos do Tesouro dos EUA em circulação mantidos pelo Federal Reserve. O rápido aumento ocorrido nos últimos meses é impressionante.

Também se observa um aumento para a segunda variável, o estoque de títulos hipotecários, emitidos pelo conjunto de empresas hipotecarias patrocinadas pelo governo (GSEs), mas em menor magnitude. Lembramos que os títulos lastreados em hipotecas são emitidos por GSEs como expressão de financiamento de crédito, aliviando a carga de empréstimos hipotecários nos ativos de bancos ou mantendo as hipotecas feitas por intermediários financeiros não bancários. 


\section{Figura 4 - Títulos detidos em definitivo pelo Federal Reserve (US\$ trilhão)}

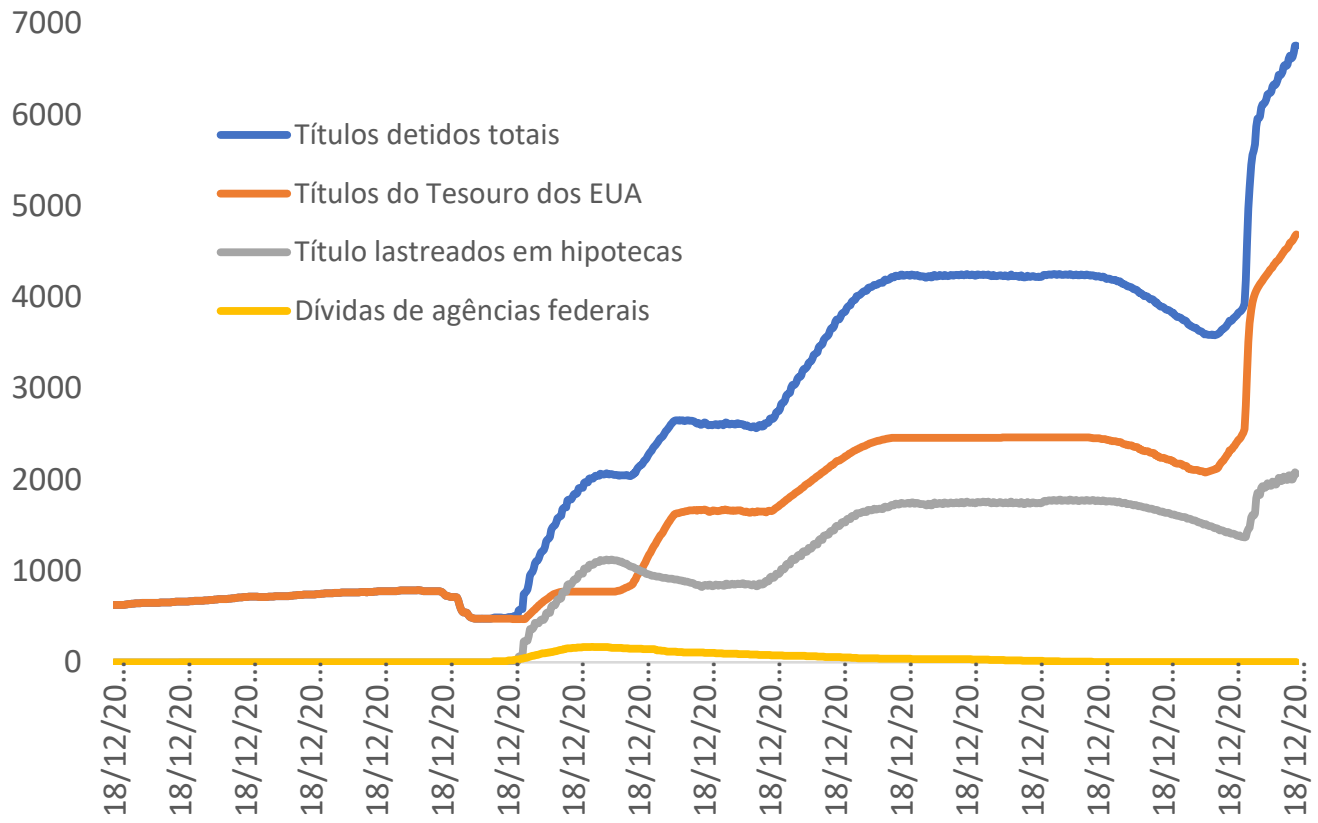

Fonte: Board of Governors of the Federal Reserve System (2020a)

Desde crise da COVID-19, o Federal Reserve passou a intervir em outros mercados secundários, como os de comercial papers. Este é um desenvolvimento completamente novo. A lista de empréstimos e valores mobiliários é mostrada na Figura 5. Os valores ainda são limitados, mas essas ações marcam uma ampliação qualitativamente nova das intervenções por parte do Federal Reserve. A Figura 6 ilustra a impressionante correlação entre o fluxo semanal de novos casos da Covid e os fluxos de linhas de crédito, na verdade uma curiosidade muito interessante. A compra de títulos pelo Federal Reserve como estratégia de enfrentamento da elevação do endividamento decorrente da crise da COVID19 não era a única opção de política econômica.

Uma saída mais radical seria a compensação direta da perda de receita de vendas das empresas por um fundo central criado para esse fim e financiado pelo Federal Reserve. Este deveria, em particular, ter sido o caso quando muitas atividades estavam proibidas, por exemplo, para restaurantes, teatros, cinemas ou transportes, etc. A forma desse apoio deveria ter sido via subsídios, sem perspectiva de reembolso, em vez de empréstimo. Não havia e ainda não há risco de inflação nestas circunstâncias. De fato, não há pagamentos dos valores mobiliários mantidos pelo Federal Reserve. Quando os títulos vencem, novos títulos são comprados e os estoques são mantidos em seu nível existente ou aumentados. Um relaxamento foi tentado em 2018, mas foi efêmero. 
Figura 5 - Linhas de crédito (empréstimos e valores mobiliários) do FED, janeiro/2020 - agosto/2020 (US\$ bilhão)

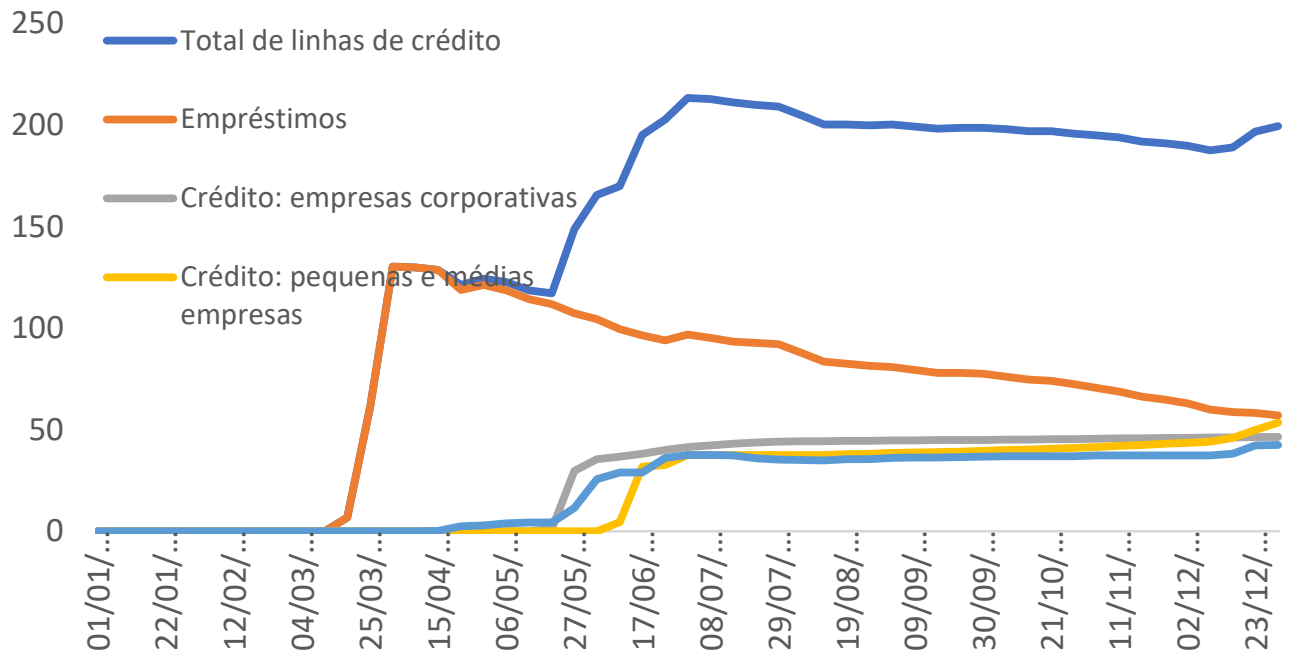

Figura 6 - Casos de COVID-19 e novas linhas de crédito (nº semanais e US\$ bilhão)

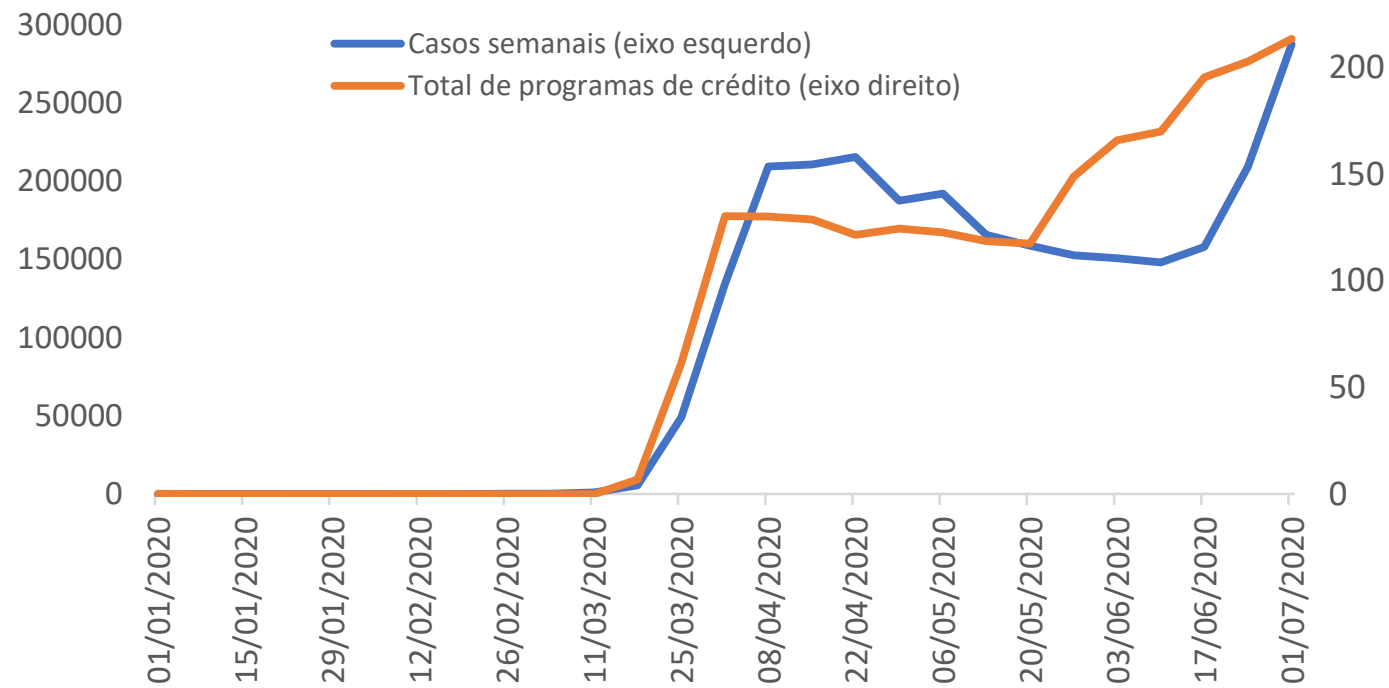

Fonte: Board of Governors of the Federal Reserve System (2020a) 


\section{A Crise e a Estrutura de Financiamento dos Mecanismos de Crédito: o Envolvimento Histórico do FED}

A compra de títulos do governo pelo Federal Reserve é um mecanismo de rotina. A Figura 7 mostra o estoque de títulos públicos mantidos pelo Federal Reserve desde a década de 1950, correspondendo consistentemente a cerca de 5\% da tendência do PIB. Ao longo do período os ativos do Federal Reserve cresceram proporcionalmente ao PIB, permitindo o crescimento da moeda em circulação (a soma dos depósitos no Federal Reserve e das notas).

A crise de 2008-9 introduziu o novo e maciço financiamento direto de déficits do governo pela compra de títulos do governo pelo Federal Reserve, dentro da chamada estrutura de política monetária não convencional. Esse mecanismo era, supostamente, transitório. A tentativa de reversão durou pouco. Com a crise da COVID-19, a reversão não estava mais na agenda. Um novo passo adiante foi realizado.

Figura 7 - Títulos detidos pelo FED: Uma visão de longo prazo, \% do PIB

20

16

12

8

4

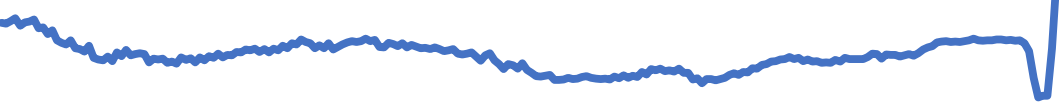

0

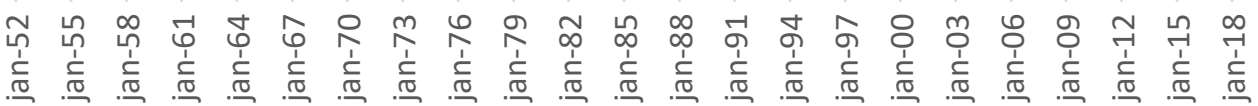

Fonte: Bureau of Economic Analysis (2020) 
Uma de nossas teses fundamentais sobre o curso histórico da macroeconomia é que a desestabilização pelas mudanças técnicas e inovações financeiras está tendencialmente em ação, e propícia potencialmente graus crescentes de instabilidade (ou seja, recessões mais frequentes e mais profundas). As ações contrárias são conduzidas pelas autoridades centrais que controlam essa tendência, na esteira de perturbações, de forma que a macroeconomia é constantemente mantida à beira de estabilidade e instabilidade, conforme expresso no ciclo de negócios.

A Grande Depressão foi uma expressão dramática desses ajustes ex post. Antes da depressão, o déficit governamental era proibido, um crime, exceto em circunstâncias de guerra. Após 1937 e a Segunda Guerra Mundial, tornou-se um instrumento padrão de política macroeconômica. O mesmo se aplica ao financiamento direto de crédito pelo Federal Reserve, também considerado um crime antes da crise de 2008-9 e, agora, um instrumento básico. E a crise da COVID-19 está multiplicando esse potencial.

\section{Dinâmica Neoliberal: a Economia dos EUA e o Resto do Mundo}

O déficit estrutural do comércio exterior está na origem de um viés insustentável na trajetória da economia neoliberal dos EUA. Como mostra a Figura 8, antes da crise de 2008-9 o déficit atingiu mais de 6\% do PIB. Em 2015, houve uma forte redução na importação de petróleo devido ao uso de gás de xisto e a queda no preço do petróleo, mas o déficit ainda era de aproximadamente $3 \%$ do PIB e está aumentando.

\section{Figura 8 - O déficit do comércio exterior, \% do PIB}

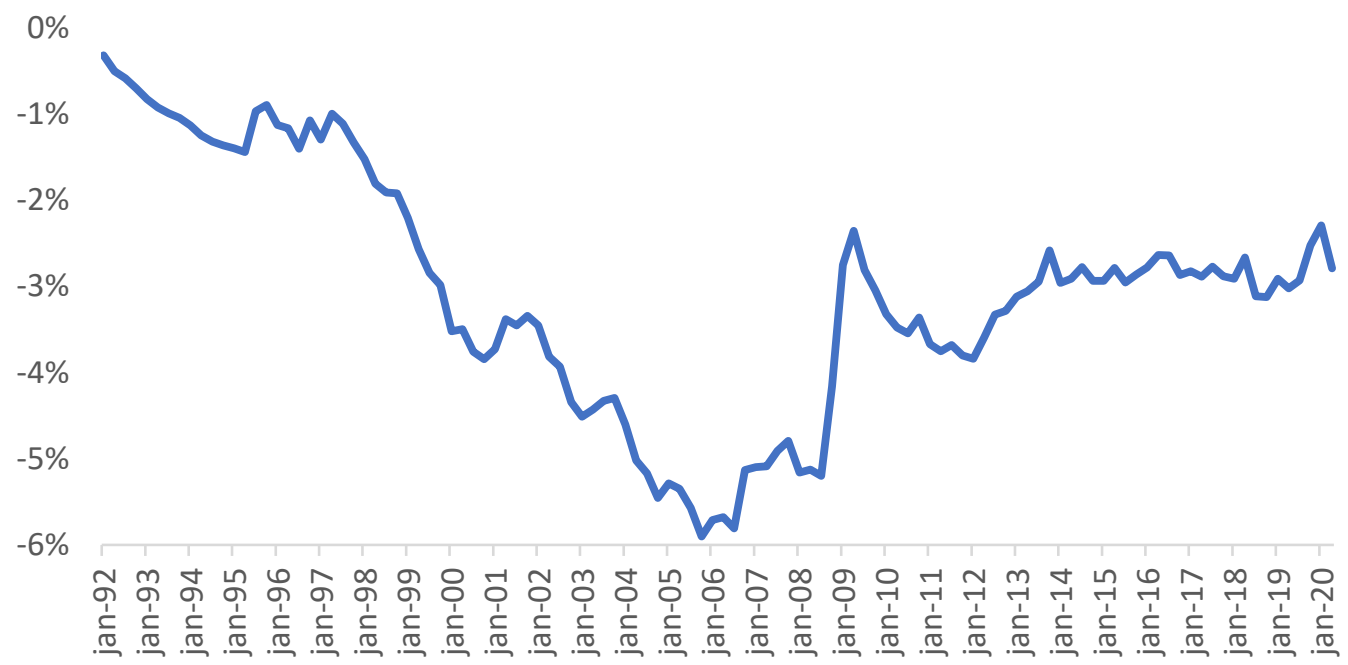

Fonte: Bureau of Economic Analysis (2020) 
A posição dos Estados Unidos na economia mundial e o papel do dólar como moeda internacional permite a continuidade dessa trajetória. A consequência é, no entanto, um grande superávit financeiro a favor de países estrangeiros. Os fluxos de investimento direto dos EUA para o resto do mundo e do resto do mundo para os Estados Unidos estão equilibrados. O restante das compras são: (i) valores mobiliários dos EUA, basicamente títulos do Tesouro e valores mobiliários emitidos por GSEs e seus associados e (ii) ações dos EUA.

$\mathrm{O}$ aumento no financiamento externo foi enorme durante as décadas neoliberais, como mostra a Figura 9. A crise de 2008-9 introduziu um período de estagnação: o resto do mundo não está vendendo massivamente títulos americanos, mas a tendência de crescimento foi interrompida subitamente, enquanto as necessidades da economia dos EUA ainda estavam aumentando. Inclusive, podemos observar um pequeno declínio nas últimas observações. As compras de títulos de dívida pelo Federal Reserve estão, na verdade, substituindo o financiamento externo, na medida em que as instituições financeiras domésticas e as famílias não eram capazes de realizar essa tarefa.

Figura 9 - O financiamento dos EUA pelo resto do mundo em títulos da dívida, \% do PIB

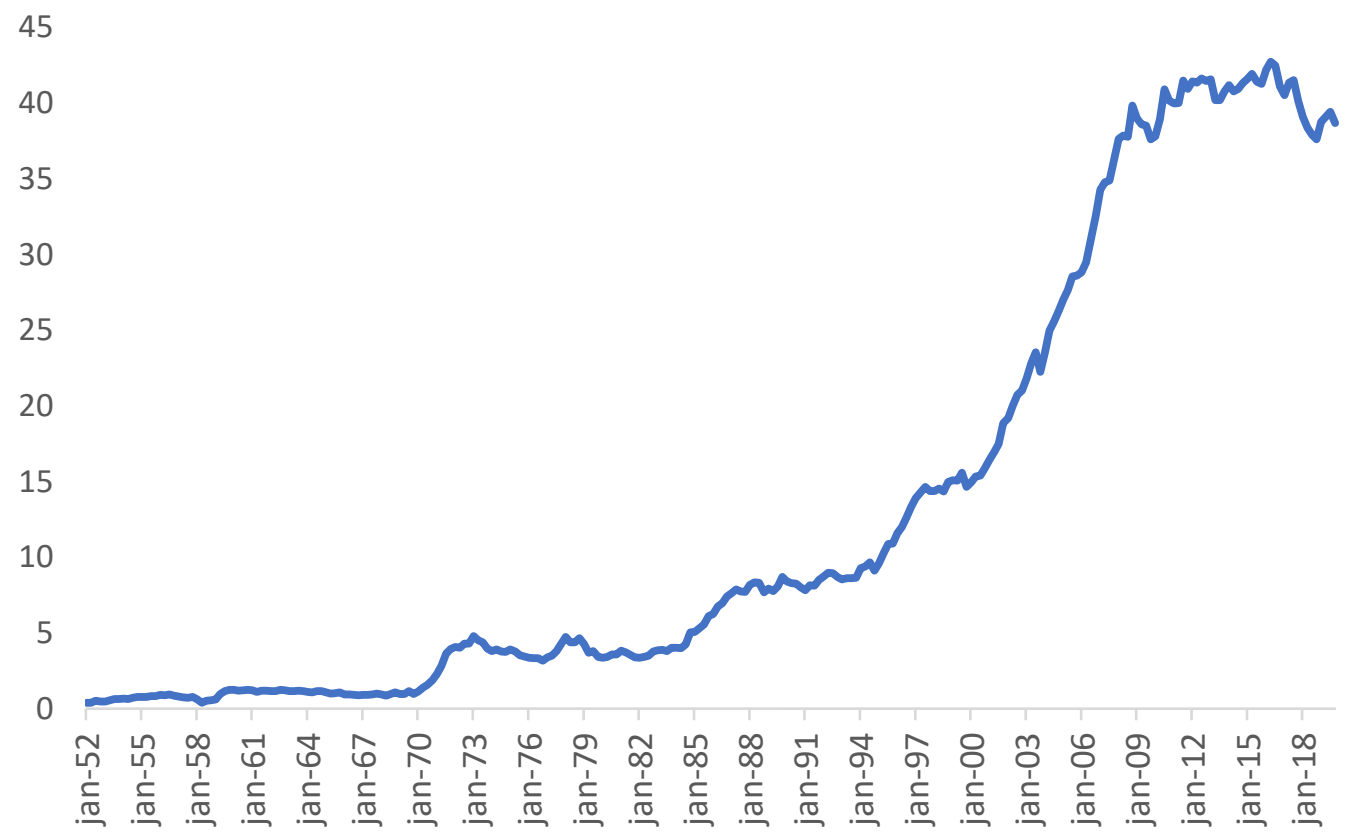

Fonte: Fonte: Bureau of Economic Analysis (2020) 


\section{Perspectivas}

O apoio dos mecanismos de crédito pelo Federal Reserve já estava em andamento antes da crise da COVID-19. Novos graus foram alcançados e novos caminhos estão sendo abertos atualmente, como empréstimos diretos às empresas pelo Fed. Os limites são, no entanto, cumpridos por razões políticas e ideológicas: Conforme mencionado anteriormente, não havia uma política voltada à preservação da receita de vendas das empresas.

A continuação da nova trajetória de taxas de juros muito baixas e o financiamento direto do Federal Reserve enfrentará fortes resistências por parte de interesses financeiros. Isso transformaria os bancos como credores em meros intermediários na concessão de empréstimos (cobrança de taxas aos mutuários), como já é o caso da intermediação financeira não-bancária. A desvalorização das dívidas por uma onda de inflação é improvável nas atuais circunstâncias políticas. Apenas uma deterioração profunda e duradoura da situação em andamento poderia levar a tais desenvolvimentos.

O efeito da crise da COVID-19 ainda não é aparente nas séries da seção anterior. O ponto central é, contudo, a nova trajetória da economia dos EUA, independentemente da crise da Covid, na qual o financiamento de crédito por parte do Federal Reserve é estruturalmente necessário, abrindo assim uma nova era. Há um forte conflito com interesses financeiros privados. Não há alternativa, exceto um afastamento radical da dinâmica neoliberal.

Nessa situação, o papel central e o privilégio das grandes instituições financeiras como gerentes de ativos, os pilares do capitalismo gerencial neoliberal, no controle de empresas não financeiras não seriam alterados, a priori. A discussão aqui efetuada focou apenas em uma faceta da trajetória da economia e da sociedade, no que diz respeito a sua trajetória de insustentabilidade. Futuras análises poderão analisar a segunda faceta que é a dinâmica da acumulação no capitalismo gerencial neoliberal.

\section{Referências}

Board of Governors of the Federal Reserve System. Factors Affecting Reserve Balances, 2020a. Disponível em: https://www.federalreserve.gov/releases/h41/

Board of Governors of the Federal Reserve System. New Security Issues, U.S. Corporations (Table 1.46), 2020b. Disponível em: https://www.federalreserve.gov/data/corpsecure/current.htm\#fn

Bureau of Economic Analysis. Nipa Tables, 2020. 
Bureau of the Fiscal Service, U.S. Department of the Treasury. The Debt to the Penny, 2020. Disponível em

https://www.treasurydirect.gov/govt/reports/pd/pd debttothepenny.htm.

Federal Reserve St. Louis. Assets of Commercial Banks in the US, 2020.

Our World in Data. United States: Coronavirus Pandemic Country Profile, 2020

Disponível em: https://ourworldindata.org/coronavirus/country/united-

$\underline{\text { states? country }=\sim \mathrm{USA}}$ 